\title{
ExperiênCIas e VivênCias de EscolarizaÇáo de Alunos com DeficiênCia INTELECTUAL $^{1}$ \\ SCHOOLING EXPERIENCES OF STUDENTS WITH INTELLECTUAL DisABILITIES
}

\author{
Rosana GLAT ${ }^{2}$ \\ Suzanli ESTEF ${ }^{3}$
}

\begin{abstract}
RESUMO: Em que pese a vasta produção científica e a disseminação das políticas de educação inclusiva, menos atenção tem sido dada à visão dos próprios sujeitos sobre suas experiências de escolarização. Este artigo apresenta um recorte de uma pesquisa que analisou o cotidiano de 30 jovens e adultos com deficiência intelectual, tendo como foco suas vivências escolares. Os dados foram produzidos, em entrevistas abertas, sem roteiro pré-determinado, com base na metodologia de História de Vida. Em consonância com estudos de campo anteriores, os relatos mostraram que alunos com deficiência intelectual, de modo geral, náo estáo tendo experiências escolares adequadas que, de fato, garantam seu desenvolvimento, participação, aprendizagem e inclusão social. A análise das suas falas, sobretudo dos que frequentaram o ensino comum, aponta, com poucas exceçóes, um percurso de dificuldades e fracasso escolar, levando, em alguns casos, ao retorno à instituiçấo especializada. A realidade retratada faz questionar a coerência entre as políticas e as propostas educacionais e a sua materializaçấo no espaço e no cotidiano escolar. A concepçáo do processo de ensino e aprendizado, a composiçâo curricular e as práticas pedagógicas predominantes, assim como as representaçóes sociais docentes sobre esse público, ainda são impregnadas pela cultura meritocrática e classificatória, incompatível com uma educação para diversidade. Ressalta-se que a escuta e o feedback desses estudantes, alvos das políticas e dos programas, deve ser o ponto de partida para o desenvolvimento de procedimentos e de estratégias pedagógicas que estejam, de fato, em consonância com a perspectiva de inclusão escolar.
\end{abstract}

PALAVRAS-CHAVE: Escolarização. Deficiência intelectual. Autopercepção. Histórias de vida.

\begin{abstract}
Despite the vast scientific production and the dissemination of inclusive education policies, less attention has been paid to the subjects' own view of their schooling experiences. This article presents an excerpt from a research that analyzed the daily lives of 30 youths and adults with intellectual disabilities, with the focus on their school experiences. Data were produced in open interviews, without a predetermined script, based on the Life History methodology. In line with previous field studies, the accounts showed that students with intellectual disabilities, in general, are not having adequate school experiences that, in fact, guarantee their development, participation, learning and social inclusion. The analysis of their speeches, especially of those who attended common education, points out, with few exceptions, a course of difficulties and school failure, leading in some cases to the return to the specialized institution. The reality portrayed makes us question the coherence between educational policies and proposals and their materialization in the daily school space. The teaching and learning process conception, the curricular structure, and the predominant pedagogical practices, as well as the teachers' social representations about this public, are still impregnated by the meritocratic and classificatory culture, incompatible with an education for diversity. It is emphasized that listening to the feedback from these students, targets of policies and programs, should be the starting point for the development of procedures and pedagogical strategies that are, in fact, in line with the perspective of school inclusion.
\end{abstract}

KEYWORDS: Schooling. Intellectual disability. Self-perception. Life stories.

\footnotetext{
${ }^{1}$ https://doi.org/10.1590/1980-54702021v27e0184

${ }^{2}$ Doutora pela Fundação Getúlio Vargas do Rio de Janeiro (FGV). Mestre pela Northeastern University (Boston, USA). Professora Titular da Faculdade de Educação e do Programa de Pós-Graduaçáo em Educação (PRoPEd) da Universidade do Estado do Rio de Janeiro (UERJ). Pesquisadora do Conselho Nacional de Desenvolvimento Científico e Tecnológico (CNPq). Cientista do Nosso Estado da Fundação de Amparo à Pesquisa do Estado do Rio de Janeiro (FAPERJ). Procientista da UERJ. Rio de Janeiro/Brasil. E-mail: rosanaglat@gmail.com. ORCID: https://orcid.org/0000-0002-0186-1342

${ }^{3}$ Doutoranda e Mestre em Educação pelo Programa de Pós-Graduação (PRoPEd). Faculdade de Educação na Universidade do Estado do Rio de Janeiro (UERJ). Bolsista pela Fundação de Amparo à Pesquisa do Estado do Rio de Janeiro (FAPERJ). Rio de Janeiro/Brasil. E-mail: suzanli_estef@hotmail.com. ORCID: https://orcid.org/0000-0003-3354-6598
} 


\section{INTRODUÇÁo}

A produção científica sobre inclusão escolar de alunos com deficiências é vasta, compreendendo diferentes metodologias, tais como pesquisas etnográficas, análises documentais e bibliográficas, observaçóes de campo, entrevistas com docentes e equipe escolar etc. A maioria desses estudos tem tido como foco a implantação das políticas de inclusão e as práticas pedagógicas dirigidas a esse alunado no cotidiano escolar (Antunes et al., 2011; Glat \& Pletsch, 2012; Mascaro, 2017; Nunes \& Manzini, 2020, Oliveira, 2018; Pletsch, 2014; Santos \& Martins, 2015; Segabinazi \& Mendes, 2017; Silva et al., 2016; entre outros). Entretanto, menos atenção tem sido dada às vozes dos próprios alunos e às suas experiências de escolarização.

Embora haja um conjunto de trabalhos científicos, nacionais e internacionais, privilegiando a visão dos próprios sujeitos (Agran et al., 2016; Anderson \& Bigby, 2017; Antunes, 2012; Carlou, 2019; Castanheira, 2014; Gai, 2008; Kåhlin et al., 2015; Oliveira \& Campos, 2016; etc.), ainda há carência de estudos mais aprofundados que investiguem os efeitos da disseminação das políticas de inclusão na ressignificação da identidade pessoal e no cotidiano de pessoas com deficiência, e em específico, deficiência intelectual. Tal conhecimento é imprescindível para o desenvolvimento de programas que contribuam para que esses indivíduos possam usufruir de uma melhor qualidade de vida, estabelecer relaçóes pessoais mais equânimes e participar com maior autonomia nos diferentes espaços sociais.

O presente texto apresenta um recorte de uma pesquisa (Glat, 2020) que analisou os impactos das atuais políticas de inclusão na autopercepção, cotidiano e expectativas de jovens e adultos com deficiência intelectual, a partir de seus relatos pessoais. Seguindo os pressupostos da metodologia de História de Vida, os dados foram produzidos em entrevistas abertas, nas quais os sujeitos priorizaram os aspectos de suas vidas que consideravam mais relevantes. Nesse sentido, o estudo abarcou diferentes dimensóes que compóem a experiência existencial desse público, representados pelas seguintes categorias temáticas: autopercepção, família, autonomia, trabalho, lazer, relacionamentos amorosos, escolarizaçáo, expectativas e planos para o futuro.

Ao entendermos que políticas e práticas de inclusão são operacionalizadas e direcionadas a pessoas reais em suas inter-relaçóes nos diferentes espaços sociais, e que os sujeitos que as vivenciam são as mais importantes fontes de dados, reconhecemos a relevância que a análise de tais fatores adquire no planejamento, na implementação e na avaliação de programas dirigidos a esse público.

Para contribuir com a discussão atual sobre modelos educacionais para estudantes com deficiência e complementar estudos anteriores (Estef, 2016; Glat \& Estef, 2018; Glat et al., 2009; Glat \& Pletsch, 2012; Marin, 2015; Mascaro, 2017; Oliveira; 2018), neste artigo teremos como foco o processo de escolarização, a partir da visão e da experiência pessoal dos próprios alunos com deficiência intelectual.

\section{Percurso investigativo}

A referida pesquisa foi realizada com base na metodologia de História de Vida (Bertaux, 2010; Glat et al., 2004; Glat, 2009; Reis, 2019). Esse método considera como única 
fonte de dados a história de vida, determinados aspectos ou acontecimentos conforme narrados pelo sujeito, em entrevistas abertas, isto é, sem roteiro pré-determinado.

Foram entrevistados 30 jovens e adultos com deficiência intelectual, de ambos os sexos, residentes nos estados do Rio de Janeiro e Amazonas. Suas idades variavam entre 17 e 52 anos, sendo a faixa etária predominante dos 20 aos 29 anos. Nos primeiros contatos, os sujeitos foram informados sobre os objetivos e os procedimentos do estudo. Aqueles que se dispuseram a participar assinaram um Termo de Consentimento Livre e Esclarecido (TCLE) ${ }^{4}$.

Antes de iniciar a entrevista propriamente dita, foi reafirmado ao sujeito que sua identidade seria preservada, o que ele dissesse náo seria divulgado, era livre para discorrer sobre o que tivesse vontade e poderia interromper a qualquer momento. Seguindo os procedimentos básicos do método de História de Vida, pedia-se ao participante para falar um pouco sobre sua vida, sobre o que considerasse importante. De acordo com as suas colocaçóes, a entrevistadora formulava, na hora, algumas perguntas para aprofundar ou esclarecer determinado ponto. Contudo, a direção da conversa e os tópicos que iam ser abordados eram sempre de iniciativa espontânea do sujeito. As entrevistas terminavam quando ele deixava claro não ter nada mais a dizer.

Todas as entrevistas foram gravadas em áudio, com autorização dos participantes, e depois transcritas textualmente. A partir da transcrição das entrevistas, foram identificados conteúdos específicos, posteriormente agrupados em categorias temáticas para análise. Inicialmente, foram separados, das narrativas individuais, os elementos que melhor atendiam aos objetivos da pesquisa. A seguir, eles foram agrupados em categorias ou eixos temáticos, passando-se, então, à análise interpretativa, propriamente dita do material (Glat, 2020; Pletsch, 2014).

\section{VIVÊNCIAS DE ESCOLARIZAÇÁO}

Nas entrevistas realizadas, 23 dos 30 sujeitos (77\%) falaram espontaneamente sobre suas experiências escolares, demonstrando a relevância do tema. Por meio de seus relatos, pudemos identificar percursos diferenciados, que correspondem às alternativas educacionais voltadas às pessoas com deficiência intelectual.

Um grupo, embora não majoritário na nossa amostra, mas que tende a se tornar mais numeroso com a consolidação das políticas de Educação Inclusiva, frequentou apenas o ensino comum.

Eu entrei para o primeiro. Eu tava no C.A. no outro colégio e entrei logo no primeiro ano no ... Esse colégio tem me ajudado em muito, e até agora esse colégio tá me ajudando. (João, 23 anos $)^{5}$

\footnotetext{
${ }^{4}$ No caso de menores de idade e/ou indivíduos legalmente interditados, foi solicitada autorizaçăo dos responsáveis por meio do TCLE, e disponibilizado aos sujeitos o Termo de Assentimento (TA).

5 Todos os nomes são fictícios.
} 
É preciso levar em consideração, entretanto, que grande parte das crianças e dos jovens com deficiência intelectual apresenta uma trajetória contínua de fracasso escolar, passando por diversas escolas, como ilustrado pelas narrativas a seguir.

Eu já passei pelas outras escolas. Aí, nas outras escolas, não deixavam eu passar. (Alex, 28 anos) Aí passou muitos anos... aí quando tinha 18 anos que eu voltei a estudar de noite pra me alfabetizar, fiz CA... passei aí, depois fui pra primeira. Aí quando ia pra segunda [...] aí começou a ficar complicado e eu não consegui aprender. (Marina, 44 anos)

Assim, ao não se adaptarem à dinâmica e às práticas pedagógicas do ensino comum, muitos estudantes com deficiência intelectual são encaminhados para o ensino especial. Vale ressaltarmos que, frequentemente, sobretudo nos casos com menor comprometimento, é o fracasso escolar que elicita o diagnóstico de deficiência intelectual (Glat, 2009), o que, por sua vez, pode levar à sua transferência a um espaço educacional mais segregado, na medida em que a escola não produz adaptaçóes ou flexibiliza currículos para atender às suas necessidades educacionais específicas.

Lá têm pessoas com deficiência, outros são cadeirantes; uns consegue falar, outros não. É uma escola especial. Antes eu estudava em escolas comuns. Eu já estudei no (nome da escola comum) aí me transferiram pra essa escola [escola especializada] por causa da idade. (Renata, 21 anos) ... eu estudo há quatro anos nessa escola... antes eu estudava em uma escola normal... (Glória, 30 anos)

Eu estudo aqui desde 2012. Antes daqui eu estudava em frente à Dutra na escola (nome da escola) ... escola normal... (Leo, 21 anos)

Mesmo em plena vigência do modelo de educação inclusiva, ainda há um número significativo de indivíduos com deficiência intelectual cuja trajetória educacional se restringe à escola ou à instituição especializada.

Aí, a minha mãe percebeu que eu tinha algo a mais, meus familiares logo perceberam, porque uma delas era médica e ela estudou para isso. Desde então, eu entrei na APAE desde idade de seis anos, eu entrei na APAE. (Silvino, 34 anos)

[...] e aqui eu estou aqui desde os 14 anos... e aqui eu fiquei, e eu já estou aqui há 12 anos... isso tudo que eu estou aqui...é muito tempo né?. (Breno, 33 anos)

Eu entrei aqui ainda pequena, aqui eu fiquei, cresci aqui. Não estudei em nenhuma escola antes, só aqui. (Tatiana, 25 anos)

Uma das críticas que se faz ao ensino especial é que, por não seguir as diretrizes curriculares e não ter uma terminalidade definida, acaba se tornando um fim em si. De fato, ainda encontramos muitos alunos em idade adulta, como alguns dos entrevistados, que permanecem anos a fio na mesma instituição ou escola especializada, com pouco avanço na sua escolarização. Entretanto, com a consolidação das políticas de inclusão escolar, tem sido cada vez mais frequente a transferência de alunos da escola ou classe especial para o ensino comum, onde, apesar das dificuldades, alguns conseguem ter um bom desempenho.

Eu estudava lá (escola especial), aí eu saí de lá, porque eu era esperto, eu fazia tudo certinho. Eu também estudei em outra escola de Ensino Médio. (Vagner, 25 anos)

Eu estudava na $\mathrm{APAE}$, mas a minha mãe me tirou, porque eu não aprendia nada. Eu fiquei um bom tempo sem estudar, acho que foi uns cinco ou sete anos, por aí ... aí vim pra escola, 
escola normal...na escola normal. Aí, foi quando ela me pôs na escola normal e aí eu comecei a aprender. Eu sei ler, escrever...Eu estou no segundo grau. (Davi, 31 anos)

Como discutido, muitos alunos com deficiência intelectual fracassam no ensino comum e são encaminhados para a escola especial ou abandonam os estudos, devido a dificuldades de aprendizagem, inerentes à sua própria condição, que os impedem de acompanhar a dinâmica da classe. Apesar das diretrizes educacionais, grande parte das escolas ainda não apresenta uma transformação efetiva nas práticas pedagógicas que possibilite o seu desenvolvimento acadêmico (Braun \& Marin, 2012; Glat \& Pletsch, 2012; Souza, 2013). Desse modo, o aluno está inserido na turma comum, mas não participa efetivamente dos processos de ensino e de aprendizagem. Ele fica à margem da programação desenvolvida por seus colegas, com atividades descontextualizadas em relação à proposta curricular.

\begin{abstract}
Eu estudava no [nome da escola] ... Era um pouquinho pior do que aqui...lá os professores nem ligavam... só botavam a matéria no quadro e tipo assim, se vira. (Saulo, 18 anos)

[...] era uma mesa separada pra quem não sabia e pra quem sabia. Por exemplo, tem um papel, tem um texto, uma história, se você não sabe como, como é que você vai fazer o negócio se você não sabe ler e escrever? Aí ela falava pra gente que não queria ensinar porque a gente era burro e não ia conseguir aprender. (Marina, 44 anos)
\end{abstract}

A prática de separar os alunos em grupos por nível de conhecimento, conforme o relato anterior, era uma estratégia utilizada por muitos professores para lidar com alunado diversificado no início do processo de inserção de alunos com deficiências no ensino comum (Machado, 2005). No modelo de Integração vigente até meados da década de 1990, não havia, pois, qualquer tipo de adaptaçáo ou flexibilização curricular para atender a esses estudantes.

$\mathrm{Na}$ Educação Inclusiva, porém, é a escola que deve se transformar para atender a todos os alunos, e náo estes que precisam se adaptar à escola (Glat \& Blanco, 2015). No entanto, para poder ser, de fato, efetivada, essa proposta demanda o desenvolvimento de práticas pedagógicas diferenciadas que possibilitem a aprendizagem do conteúdo escolar por alunos com necessidades educacionais especiais, sobretudo deficiência intelectual (Mascaro, 2017; Pletsch \& Glat, 2013).

Os trechos a seguir mostram exemplos, sob a óptica dos próprios alunos, dos efeitos da prática pedagógica do professor na sua aprendizagem e a sua percepçấo sobre o processo de escolarização. Esses dados indicam que, independentemente de condições intrínsecas, a atuação docente é fator decisivo na aprendizagem. Indo mais além, a postura do professor e sua convicção sobre as possibilidades ou descrença no potencial de desenvolvimento do aluno determinará em grande parte seu encaminhamento pedagógico.

Foi muito diferente, a professora era muito simpática, ela ia na lá frente, e ensina a gente direitinho. Ela tinha muita paciência. Ela não separa a gente de quem sabia e de que não sabia, ela tratava todo mundo igual. [...] com ela eu consegui aprender a ler, antes eu achava que eu náo ia conseguir por causa da professora. Aí eu consegui fazer as coisas que eu náo sabia. Isso foi muito importante. Eu gostei muito de ter aprendido a ler e escrever. (Marina, 44 anos)

$\mathrm{O}$ professor me ajuda. Eu não gosto de matemática. Eu fui reprovado, no caso. Só fala em número, raiz quadrada, expressóes algébricas e eu não sou bom em matemática. [...]. Eu peço 
ajuda ao professor de matemática... ele me ajuda mais ou menos. [...]. Quando professor de matemática, tipo assim, ele pode passar da $\mathrm{A}$ até a $\mathrm{F}$ mas têm vezes ele passa o alfabeto todo [...]. Depois ele explica os exercícios todos. Mas eu não consigo acompanhar. Os outros alunos também não conseguem acompanhar [...]. (Saulo, 18 anos)

É inquestionável que alunos com deficiência intelectual dificilmente terão condições de acompanhar a dinâmica do ensino comum sem flexibilizaçóes pedagógicas que atendam diretamente às suas necessidades educacionais especiais. Embora não tenha sido um aspecto ressaltado na maioria das entrevistas, alguns sujeitos que viveram o processo de escolarizaçáo comentaram positivamente sobre os suportes especializados que recebiam.

Aqui eu tenho algumas aulas de apoio. (Saulo, 18 anos)

[...] esse colégio tem me ajudado em muito, e até agora esse colégio tá me ajudando. (João, 23 anos)

Eu faço sala de recursos de tarde duas horas... Depois vou pra aula de noite seis horas... (Marcelo, 17 anos)

Conforme estabelecido na Declaração de Salamanca (Organização das Nações Unidas para a Educação, a Ciência e a Cultura [Unesco], 1994) e outros documentos internacionais e nacionais, a Educação Inclusiva tem como pressuposto básico educação para diversidade. A grande contradição na implementação das políticas de inclusão escolar é, justamente, acolher e trabalhar com a heterogeneidade do alunado em um sistema ainda baseado na homogeneização e na meritocracia, com currículos fechados e critérios temporais de aprovação /reprovação pré-estabelecidos.

Nesse sentido, entendemos que, sem uma diferenciação ou flexibilização de objetivos e métodos pedagógicos, a maioria dos estudantes com deficiências, sobretudo aqueles que apresentam dificuldades intrínsecas de aprendizagem, dificilmente alcançarão um patamar mínimo de êxito acadêmico (Marin \& Braun, 2020; Muniz \& Galvani, 2020; Perrenound, 1999; Tomlinson, 2008).

Um dos desafios para a viabilidade da inclusão de alunos com deficiência intelectual no ensino comum, com suas dinâmicas e diretrizes curriculares, materializa-se no processo de avaliação da aprendizagem, cujos resultados sancionam o sucesso ou o fracasso dos estudantes, em muitos casos, como comentado, levando à sua exclusão do sistema. É a avaliação que define quem são os considerados bons alunos e aqueles que não apreendem o conteúdo, mede graus de conhecimento ou de domínio e distingue aqueles que são capazes e os que não são capazes de progressão no universo escolar (Estef, 2016).

Vasconcelos (2014) lembra que o processo de avaliação instituído na maior parte das instituiçóes de ensino é de natureza classificatória e excludente, na medida em que o foco sai da aprendizagem, do desenvolvimento humano e é concentrado na nota, na aprovação e na reprovação, gerando danos, muitas vezes irreversíveis na história de vida dos estudantes.

Eu não gosto de matemática. Eu fui reprovado, no caso. [...] era para mim tá no nono ano já, já era para eu ter terminado. Mas esse ano eu fiquei retido de novo por causa da matemática, [...] eu tive recuperação $[. .]$, ...o professor explicava melhor na recuperação, mas eu não consegui tirar a nota pra passar, mesmo estudando em casa. (Saulo, 18 anos) 
Podemos assim considerar que, para além de uma diferenciação ou flexibilização do ensino, grande parte desses estudantes demandará algum nível de adaptação dos métodos e dos procedimentos avaliativos, seja de conteúdo, de forma, de tempo e/ou de espaço de realização das provas e testes (Estef, 2018; Oliveira et al., 2013).

[...] quando eu cheguei na escola, eu tinha muita dificuldade, [...] no dia da prova eu, eu faço, eu não faço em sala, mas eu faço, é... separado, e lá eu tô fazendo a prova uma por dia. A prova é separado, porque se eu fizer a prova junto com eles eu náo consigo me concentrar. (João, 23 anos)

Não resta dúvida de que a avaliação é uma questão complexa, sendo tema constante nos debates educativos. Ainda são necessárias pesquisas de campo mais sistemáticas que elucidem como os alunos com necessidades educacionais especiais têm se apropriado dos conteúdos escolares, como aferir se houve aprendizagem significativa e de que forma eles podem expressar esse aprendizado.

Autores como Esteban (2000), Hoffman (2008) e Szymanski (2016), bem como documentos oficiais (Lei no 9.394, de 20 de dezembro de 1996; Parâmetros Curriculares Nacionais: introdução aos parâmetros curriculares nacionais, 1997; Resoluçãa CNE/CEB no 2, de 11 de setembro de 2001) apontam que a avaliação do desempenho escolar deve ser vista como um processo que permite conhecer a forma como os alunos aprendem. Seguindo essa linha de reflexão, compreendemos a avaliação como uma prática que resulte em estratégias de intervenção pedagógica que flexibilizem o ensino, considerando as adaptaçôes necessárias para contemplar a singularidade de cada sujeito, sem deixar de atender ao processo de escolarização.

Uma estratégia norteadora para organizar a avaliação escolar de alunos com deficiência intelectual, ou outras necessidades educacionais especiais, é o chamado Plano Educacional Individualizado (PEI), que direciona os objetivos curriculares para o processo de ensino de um determinado sujeito. Em termos gerais, o PEI consiste em um documento que possibilita delinear, acompanhar e avaliar o desenvolvimento do aluno em relação ao planejamento didático pedagógico, em toda a sua trajetória escolar, inclusive facilitando a transição para a vida pós-escola (Mascaro, 2017; Pletsch \& Glat, 2013; Tannús-Valadão \& Mendes, 2018). O comentário a seguir, de um sujeito que estuda em uma escola comum, mostra a relevância do uso desse tipo de instrumento:

[...] esse colégio tem me ajudado em muito, e até agora esse colégio tá me ajudando. Eu tenho um relatório, tudo meu no relatório [...], todos os meus documentos, guardados lá né, de mim né. (João, 23 anos)

A partir de 2008, com a consolidação das políticas de inclusão escolar e demais legislaçóes e programas governamentais (Política Nacional de Educação Especial na Perspectiva da Educação Inclusiva [PNEEPEI], 2008; Resolução CNE/CEB no 4, de 2 de outubro de 2009; Decreto n 7.611, de 17 de novembro de 2011; Lei no 13.146, de 6 de julho de 2015), o Atendimento Educacional Especializado (AEE) em suas diferentes modalidades ${ }^{6}$ tornou mais

\footnotetext{
${ }^{6}$ Ao contrário do que tem preconizado o Ministério da Educação (MEC), cabe observarmos que o Atendimento Educacional Especializado não se restringe à Sala de Recursos Multifuncionais, podendo ser realizado na forma de diferentes modalidades tais como bidocência, mediação de aprendizagem, ensino itinerante, entre outras (Glat \& Pletsch, 2012).
} 
favorável o aprendizado de estudantes com necessidades educacionais especiais no ensino comum. Alguns dos entrevistados pontuaram que recebem suporte na escola, porém não obtivemos dados suficientes para avaliar os efeitos do AEE ou demais recursos ofertados no âmbito da escola comum.

Outras pesquisas, que também tiveram como objeto de estudo as concepçóes dos próprios estudantes, mostram a relevância e até dependência desses serviços para a aprendizagem de sujeitos com deficiência intelectual (Castanheira, 2014; Gai, 2008).

Ah! Na sala de recursos? Ah, o dever eu não faço na sala de aula [...] O dever que eu não faço na sala de aula, eu chego lá na sala de recursos e faço com a J (nome da professora).

Você acha que o trabalho na sala de recursos ajuda o trabalho que você faz na sala?

Ajuda! Porque quando ela tá lá eu faço os dever da sala todo. Quando ela não tá, eu não faço. Eu tento, mas eu não consigo [...] A sala de recursos me ajuda muito. Eu, eu consigo, eu consigo fazer muitas coisas com a sala de recursos. (Castanheira, 2014, p. 74-75)

Para todos os estudantes, independentemente de ter ou não uma deficiência, a escola é um dos espaços primordiais de socialização. Logo, como esperado, o relacionamento com colegas e professores foi tema bastante frequente nos relatos, tantos dos que estudam na escola comum como na especial.

Eu gosto daqui..., amigos...Ah... sempre estudei aqui... na mesma escola...sempre... (Alberto, 31 anos, escola especial)

Olha na escola, os professores contavam para minha mãe que eu era uma aluna muito esforçada que eu gostava muito de estudar, sempre me dei muito bem com eles. Os meus amigos, eu conversava com todos e todos eles gostavam de mim assim. Eu ainda tenho todos no Face. (Bruna, 25 anos, escola comum)

Eu gosto de todos os professores. Eu me dou bem com todo mundo. Eu sinto saudades da escola nas férias. Eu gosto de vir para escola. (Marcelo, 17 anos, escola comum)

Alguns sujeitos que estudam na escola comum relataram a ajuda que recebem de seus colegas de turma. A colaboração entre estudantes, denominada por alguns autores de "aprendizagem cooperativa" ou "sistema de tutoria por pares, no qual um aluno mais adiantado no processo auxilia um colega que ainda está elaborando o conceito em foco na atividade" (Fontes et al., 2015, p. 92), é uma excelente estratégia para incentivar a participação e a aprendizagem.

É legal ficar com meus amigos, isso é legal, tenho muitos amigos. A Evelyn ela é legal melhor amiga, porque eu a ajudo matemática, ela me ajuda na tarefa de português, geografia, ciências. (Kiara, 23 anos)

Eles [os professores] não me ajudam em sala. Meus colegas ajudam. [...]. Os outros alunos também não conseguem acompanhar. Só a Lívia que consegue acompanhar. Aí ela me ajuda às vezes. (Saulo, 18 anos)

Chama atenção, nesse último relato, que os alunos com deficiência não são os únicos que apresentam dificuldades em seguir a metodologia e a dinâmica das aulas. Certamente, grande parte dos estudantes beneficiar-se-ia de práticas pedagógicas flexibilizadas. Entretanto, a solidariedade, na escola comum, nem sempre é uma realidade. Também houve depoimentos de discriminação, exclusão e até mesmo bullying, o que reflete a "materialização de variadas formas 
de violência, veladas ou não, físicas e/ou simbólicas” (Reis et al., 2019, p. 12) que pessoas com deficiência enfrentam no seu dia a dia.

Antigamente, quando eu estudava no Ensino Fundamental, eu tinha bullying. (Hugo, 25)

Tinha quatro contra mim, quando eu era da turma, eles náo gostavam de mim, [...] estavam me fazendo negócio de maldade, me chamando de doente, de maluco. (Allan, 28 anos)

Mas eu gostava mais ou menos de lá [escola]. Porque lá onde eu estudava eu sofria preconceito.

Porque eu era diferente. Aí eu sofria muito com isso. (Roberta, 21 anos)

Nas outras...eu não gostava muito das outras escolas porque não tinha amigos... eu ficava de lado... sempre sozinha. (Mariana, 33 anos)

Embora nas entrevistas realizadas tivessem sido feitas várias referências positivas aos professores, alguns sujeitos que frequentaram o ensino comum apontaram a descrença em relação às suas possibilidades de aprendizagem.

Aí ela [a professora] falava pra gente que não queria ensinar porque a gente era burro e não ia conseguir aprender. (Marina, 44 anos)

As professoras de lá [escola comum] também eu não gostava, elas não gostavam de mim. (Bernardo, 33 anos).

Conforme observado em estudos anteriores (Glat \& Pletsch, 2012; Glat, 2016), é ainda bastante arraigado o preconceito dos professores, que se manifesta na baixa expectativa acadêmica em relação a esses alunos. Essa atitude docente de discriminação é sentida por eles, aumentando sua baixa estima e menos valia, fatores que afetam e dificultam ainda mais sua aprendizagem.

\section{REFLEXÓES FINAIS}

Este artigo apresenta um recorte de uma pesquisa que analisou o cotidiano de jovens e adultos com deficiência intelectual, tendo como foco suas vivências e experiências de escolarização. Os dados foram produzidos em entrevistas abertas nas quais os sujeitos eram livres para falar espontaneamente sobre diferentes aspectos de suas vidas, sem direcionamento, trazendo à tona o que, de fato, era significativo para eles.

Os relatos dos participantes que frequentaram o ensino comum, confirmando dados de estudos prévios (Glat \& Pletsch, 2012; Pletsch \& Glat, 2013; Pletsch, 2014), mostraram que alunos com deficiência intelectual, de modo geral, não estáo tendo experiências escolares adequadas que garantam, efetivamente, sua participação, aprendizagem e favoreçam sua inclusão social. A análise das suas falas, retratando inúmeras vivências de dificuldades e fracasso escolar, faz-nos questionar, inegavelmente, a coerência entre as políticas educacionais e a sua implementação no "chão da escola".

Assim sendo, a concepção do processo de ensino e aprendizado, estruturaçáa curricular e as práticas pedagógicas predominantes na grande maioria das instituiçóes de ensino, em todos os níveis, ainda são impregnadas pela cultura meritocráticas e classificatórias disseminadas em nossos cursos de formação de professores, incompatível com uma educação para diversidade. Consequentemente, apesar das políticas e das açóes afirmativas em prol dos direitos de pessoas com deficiência, estas ainda encontram inúmeras barreiras para sua efetiva inclusão 
educacional e social. No caso dos estudantes com deficiência intelectual, prevalece a representação social de incapacidade cognitiva, isto é, de impossibilidade de aprendizagem, contribuindo para uma autoimagem inferiorizada, bem como limitada autonomia e participação social (Reis et al., 2019).

Cabe observarmos, conforme ilustrado em algumas falas, que os alunos com deficiência não são os únicos que apresentam dificuldades de seguir a metodologia e a dinâmica das aulas. $\mathrm{O}$ alto índice de fracasso escolar entre estudantes (Machado et al., 2015) que, aparentemente, não apresentam uma necessidade educacional especial, aponta para a urgência de uma adequação e flexibilização nas práticas pedagógicas. Em outras palavras, em uma proposta educacional que acate a diversidade, conforme previsto pelas políticas de Educação Inclusiva, a diferenciação no ensino não é dirigida somente para os alunos com deficiência, mas para todos que demostrarem dificuldade em acompanhar os conteúdos curriculares veiculados.

O ingresso ou o retorno para a escola ou instituição especializada após fracasso no ensino comum, relatado por alguns sujeitos, é um dado significativo. Representa uma tendência que ainda parece prevalecer (Glat, 2009), apesar da crescente diminuição de oferta de serviços substitutivos de Educação Especial.

Também foi constatado que alunos com deficiência intelectual, quando inseridos em espaços de escolarização ditos inclusivos, de modo geral, sofrem estigmas, discriminação e descrédito sobre suas condiçóes de interação educacional e social. Em que pesem os dispositivos legais e as evidências científicas, não têm havido impactos significativos em uma transformação das relações sociais e das práticas pedagógicas dirigidas para esse alunado.

Independentemente de críticas que possam ser feitas às instituiçôes especializadas, pela avaliação positiva que os entrevistados fizeram, também apontada em pesquisa anterior (Glat, 2009), o espaço de acolhimento, socialização e construção de conhecimento que essas instituiçóes representam não pode ser desconsiderado. Instituições especializadas, se ressignificadas, são uma alternativa profícua de educação profissional e/ou continuada para sujeitos que ultrapassaram o período regular de escolarização.

Não obstante já haja um conjunto de estudos que privilegiem a escuta de sujeitos com deficiência intelectual, assim como de outros grupos que compóem o público-alvo da Educação Especial, a relevância desta pesquisa, além da sua contribuição para o avanço da produção científica da área, consiste na sua aplicabilidade para a construção e a implementação de políticas e de práticas educacionais e sociais. Infelizmente, o lema do movimento de auto defensores mundial "Nada sobre nós, sem nós" ainda não é devidamente posto em prática na formulação de programas dirigidos a essa população (Glat, 2020).

Nesse sentido, a escuta e o feedback desses estudantes deve ser o ponto de partida para o desenvolvimento de procedimentos e de estratégias pedagógicas que estejam, de fato, em consonância com a perspectiva de inclusão escolar. A intenção é convocar outro olhar para essas práticas, cujo foco não seja mais exclusivamente nas dificuldades do aluno, mas na transformação de crenças e de representações sociais que permitam o reconhecimento de seu potencial de aprendizagem. 
Futuros estudos, aprofundando essa perspectiva epistemológica, devem ser dirigidos para obtenção de mais dados de como esses sujeitos estão passando pelo processo de escolarização no ensino comum, quais suas reais demandas, que suportes são mais efetivos, e como reconfigurar as práticas curriculares, de ensino e de avaliação.

\section{REFERENCIAS}

Agran, M., Maclean Jr., W. E., \& Andren, K. A. K. (2016) "My voice counts, too": Voting participation among individuals with intellectual disability. Intellectual and Developmental Disabilities, 54(4), 285-294. http://doi.org/10.1352/1934-9556-54.4.285

Anderson, S., \& Bigby, C. (2017) Self-advocacy as a means to positive identities for people with intellectual disability: 'We just help them, be them really'. Journal of Applied Research in Intellectual Disabilities, 30(1), 109-120. https://doi.org/10.1111/jar.12223

Antunes, K., Marin, M., \& Braun, P. (2011). Repensando a Educação Escolar: diretrizes políticas, práticas curriculares e deficiência intelectual. Ciências Humanas e Sociais em Revista, 32(1), 179189.

Antunes, K. C. V. (2012). História de Vida de alunos com deficiência intelectual:percurso escolar e a constituição do sujeito [Tese de Doutorado, Universidade do Estado do Rio de Janeiro]. Repositório BDTD/ IBICT. https://bdtd.ibict.br/vufind/Record/UERJ_91f45d3ee34d84398418d1f68da2898c

Bertaux, D. (2010) Narrativas de vida: a pesquisa e seus métodos. Paulus.

Braun, P., \& Marin, M. (2012). Práticas docentes em tempos de inclusão: uma experiência na escola básica. e-Mosaicos, 1(2), 29-43.

Carlou, A. (2019). Cotidiano social e inserção laboral de jovens e adultos com deficiência intelectual - relatos pessoais [Tese de Doutorado, Universidade do Estado do Rio de Janeiro]. Repositório BDTD/ IBICT da UERJ. http://www.proped.pro.br/\#

Castanheira, A. d. O. (2014). Deixa que eu falo: a inclusão sob a ótica do estudante com deficiência intelectual [Dissertação de Mestrado em Educação], Universidade Federal do Rio de Janeiro]. Repositório BDTD/IBICT da UERJ. https://ppge.educacao.ufrj.br/Disserta\%C3\%A7\%C3\%B5es2014/ dandr\%C3\%A9acastanheira.pdf

Decreto $\mathrm{n}^{\circ}$ 7.611, de 17 de novembro de 2011. Dispóe sobre a educação especial, o atendimento educacional especializado e dá outras providências. https://bit.ly/36xbhjD

Esteban, M. T. (2000). A avaliação no cotidiano escolar. Avaliação uma prática em busca de novos sentidos. DP \& A.

Estef, S. (2016). Concepçôes sobre os processos de avaliação escolar para alunos com necessidades educacionais especiais: sob a ótica docente [Dissertação de Mestrado, Universidade do Estado do Rio de Janeiro]. Repositório BDTD/IBICT da UERJ. http://www.proped.pro.br/\#

Estef, S. (2018). Concepçóes docentes sobre a avaliação escolar para alunos com deficiência. Revista Espaço Acadêmico, 205, 23-34.

Fontes, R. de S., Pletsch, M. D., Braun, P., \& Glat, R. (2015). Estratégias pedagógicas para a inclusão de alunos com deficiência intelectual no ensino regular. In R. Glat (Org.), Educação Inclusiva: cultura e cotidiano escolar (2。 ed., pp. 79-96). 7 Letras. 
Gai, D. N. (2008). Deficiência mental, escolarização, narrativas: a terceira margem do rio? [Dissertação de Mestrado, Universidade Federal do Rio Grande do Sul]. Repositório Digital LUME da UFRGS. https://www.lume.ufrgs.br/handle/10183/13501

Glat, R. (2009). Somos iguais a vocês: depoimentos de mulheres com deficiência mental. 7 Letras.

Glat, R. (2016). Políticas e práticas de inclusão escolar no Colégio de Aplicação da UERJ: impactos sobre a cultura escolar. Relatório técnico- Conselho Nacional de Desenvolvimento Científico e Tecnológico (CNPq).

Glat, R. (2020). Falando de si: estudos sobre auto-percepção e histórias de vida de pessoas com deficiência intelectual. Relatório técnico- Conselho Nacional de Desenvolvimento Científico e Tecnológico (CNPq).

Glat, R., \& Blanco, L. M. V. (2015). Educação Especial no contexto da Educação Inclusiva. In R. Glat (Org.). Educação Inclusiva: cultura e cotidiano escolar (2a ed., pp. 15-35). 7 Letras.

Glat, R., \& Estef, S. (2018). Inclusão escolar e organização da prática pedagógica no Colégio de Aplicação da UERJ. In M. A. Almeida (Org.), Práticas Pedagógicas Inclusivas em Contextos Escolares (pp. 13-29). ABPEE.

Glat, R., Pletsch, M. D., \& Fontes, R. de S. (2009). Panorama da Educaçáo Inclusiva no Município do Rio de Janeiro. Educação \& Realidade, 34(1), 123-136.

Glat, R., \& Pletsch M. D. (2012). Inclusão escolar de alunos com necessidades educacionais especiais. EdUERJ.

Glat, R., Santos, R. da S., Pletsch, M. D., Nogueira, M. L. de L., \& Duque, M. A. F. T. (2004). O método de História de Vida na pesquisa em Educação Especial. Revista Brasileira de Educação Especial, 10(2), 235-50.

Hoffmann, J. (2008). Avaliação, mito e desafio: uma perspectiva construtivista. Mediação.

Káhin, I., Kjellberg, A., Nord, C., \& Hagberg, J. E. (2015). Lived experiences of ageing and later life in older people with intellectual disabilities. Ageing \& Society, 35(3), 602-628. https://doi. org/10.1017/S0144686X13000949

Lei no 9.394, de 20 de dezembro de 1996. Estabelece as diretrizes e bases da educação nacional. http:// www.planalto.gov.br/ccivil_03/LEIS/L9394.htm

Lei no 13.146, de 6 de julho de 2015. Institui a Lei Brasileira de Inclusão da Pessoa com Deficiência (Estatuto da Pessoa com Deficiência). http://www.planalto.gov.br/ccivil_03/_ato2015-2018/2015/ lei/113146.htm

Machado, K. da S. (2005). A prática da inclusão de alunos com necessidades educativas especiais em classe regular: um estudo de caso com abordagem etnográfica [Dissertação de Mestrado, Universidade do Estado do Rio de Janeiro]. Repositório BDTD/IBICT da UERJ. http://www.proped.pro.br/teses/ teses_pdf/2003_1-24-ME.pdf

Machado, M. L. C., Lopes, P. S. V. C., \& Senna, L. A. G. (2015). La formación del profesordo en Brasil: entre la cultura escrita y la diversidad cultural. Revista Temas de Educación, 21(2), 311-322.

Marin, M. V. (2015). Inclusão escolar de alunos com necessidades educacionais especiais no segundo segmento do ensino fundamental em um espaço de excelência acadêmica [Tese de Doutorado, Faculdade de Educação, Universidade do Estado do Rio de Janeiro]. Repositório BDTD/IBICT da UERJ. http://www.proped.pro.br/\# 
Marin, M. V., \& Braun, P. (2020). Currículo e diferenciação pedagógica - uma prática de exclusão?. Revista Exitus, 10(1), e020010. https://doi.org/10.24065/2237-9460.2020v10n0ID1154

Mascaro C. A. A. de C. (2017). O atendimento pedagógico na sala de recursos sob o viés do plano educacional individualizado para o aluno com deficiência intelectual: um estudo de caso [Tese de Doutorado, Universidade do Estado do Rio de Janeiro]. Repositório BDTD/IBICT da UERJ. http://www. proped.pro.br/\#

Muniz, J. D., \& Galvani, M. D. (2020). Ensino colaborativo e adaptação curricular: atuação e concepçáo dos professores no processo de inclusão escolar. In E. G. Mendes (Org.), Da teoria à práxis: vivenciando a colaboração no dia a dia escolar. (pp. 15-26). ABPEE.

Nunes, V. L. M., \& Manzini, E. J. (2020). Concepção do professor do ensino comum em relação à aprendizagem, currículo, ensino e avaliação do aluno com deficiência intelectual. Revista Educação Especial, 33, 1-20. https://doi.org/10.5902/1984686X43241

Oliveira, A. A. S., Valentim, F. O. D., \& Silva, L. H. (2013). Avaliação pedagógica: Foco na deficiência intelectual numa perspectiva inclusiva. Cultura Acadêmica.

Oliveira, M. C. (2018). Colaboraçâo e inclusão escolar de alunos com necessidades educacionais especiais: elementos em diálogo para/com/sobre a produção curricular [Tese de Doutorado, Universidade do Estado do Rio de Janeiro]. Repositório BDTD/IBICT da UERJ. http://www.proped.pro.br/\#

Oliveira, P., \& Campos, J. A. de P. P. (2016). O retrato da escola segundo o olhar de jovens e adultos com deficiência intelectual matriculados na EJA regular. Interfaces da Educação, 7(19), 146-165. https:// doi.org/10.26514/inter.v7i19.1033

Organização das Nações Unidas para a Educação, a Ciência e a Cultura (1994). Declaração de Salamanca de princípios, politica e prática para as necessidades educativas especiais. CORDE.

Parâmetros curriculares nacionais: introdução aos parâmetros curriculares nacionais (1997). MEC/SEF. http://portal.mec.gov.br/seb/arquivos/pdf/livro01.pdf

Perrenoud, D. P. (1999). Avaliação: da excelência à regulação das aprendizagens. Artmed.

Pletsch, M. D., \& Glat, R. (2013). Plano Educacional Individualizado (PEI): um diálogo entre práticas curriculares e processos de avaliação escolar. In R. Glat, \& M. D. Pletsch (Orgs.), Estratégias Educacionais diferenciadas para alunos com necessidades especiais (pp. 17-34). EdUERJ.

Pletsch, M. D. (2014). Repensando a inclusão escolar: diretrizes políticas, práticas curriculares e deficiência intelectual. NAU.

Política Nacional de Educação Especial na Perspectiva da Educação Inclusiva (2008). http://portal.mec. gov.br/index.php?option=com_docman \&view=download $\&$ alias=16690-politica-nacional-deeducacao-especial-na-perspectiva-da-educacao-inclusiva-05122014\&Itemid=30192

Reis, J. G. (2019). Vozes dos "Rios" da Amazônia: história de vida de estudantes no Ensino Superior com deficiência [Tese de Doutorado, Universidade do Estado do Rio de Janeiro]. Repositório BDTD/ IBICT da UERJ. http://www.proped.pro.br/\#

Reis, J. G., Araújo, S. M., \& Glat, R. (2019). Autopercepção de pessoas com deficiência intelectual sobre deficiência, estigma e preconceito. Revista Educação Especial, 32, p. 1-16. https://doi. org/10.5902/1984686X33882

Resolução CNE/CEB no 2, de 11 de setembro de 2001. Diretrizes nacionais para a educação especial na educação básica. http://portal.mec.gov.br/cne/arquivos/pdf/CEB0201.pdf 
Resolução CNE/CEB no 4, de 2 de outubro de 2009. Institui Diretrizes Operacionais para o Atendimento Educacional Especializado na Educação Básica, modalidade Educação Especial. http://portal.mec. gov.br/dmdocuments/rceb004_09.pdf

Santos. T. C. C., \& Martins, L. A. R. (2015). Práticas de professores frente ao aluno com deficiência intelectual em classe regular. Revista Brasileira de Educação Especial, 21(3), 395-408. https://doi. org/10.1590/S1413-65382115000300006

Segabinazi, M., \& Mendes, G. M. L. (2017). Caminhos possíveis em contextos reais: o Programa de Implantação das Salas de Recursos Multifuncionais na perspectiva de análise da tradução de políticas. Revista Práxis Educativa, 12, 808-825. https://doi.org/10.5212/PraxEduc.v.12i3.007

Silva, C., Hostins, R. C. L., \& Mendes, R. da S. (2016). O lugar do Atendimento Educacional Especializado nas práticas culturais de escolarização em contextos de inclusão escolar. Revista Linhas, 17(35), 10-29. http://doi.org/10.5965/1984723817352016010

Souza, F. F. (2013). Políticas de educação inclusiva: análise das condiçôes de desenvolvimento dos alunos com deficiência na instituição escolar [Tese de Doutorado, Universidade Estadual de Campinas]. Repositório da UNICAMP. http://repositorio.unicamp.br/jspui/handle/REPOSIP/250860

Szymanski, M. L. S. (2016). Sentidos e desafios da avaliação educacional. EDUNIOESTE.

Tannús-Valadão, G., \& Mendes, E. G. (2018). Inclusão escolar e o planejamento educacional individualizado: estudo comparativo sobre práticas de planejamento em diferentes países. Revista Brasileira de Educação, 23, p. 1-18. https://doi.org/10.1590/s1413-24782018230076

Tomlinson, C. A. (2008). Diferenciação pedagógica e diversidade. Ensino de alunos em turmas com diferentes niveis de capacidades. Porto Editora.

Vasconcelos, C. S. (2014). Avaliação classificatória e excludente e a inversão fetichizada da função social da escola. In C. O. Fernandes (Org.), Avaliação das aprendizagens: sua relação com o papel social da escola (pp. 17-56). Cortez. ${ }^{7}$

Recebido em: 12/09/2020

Reformulado em: 05/10/2020

Aprovado em: 21/10/2020 